Kansas State University Libraries

New Prairie Press

\title{
CHARACTERIZING FORAGING PATTERNS AMONG CATTLE AND BONDED AND NON-BONDED SMALL RUMINANTS USING SPATIAL POINT PROCESS TECHNIQUES
}

D. M. Anderson

L. W. Murray

P. Sun

E. L. Fredrickson

R. E. Estell

See next page for additional authors

Follow this and additional works at: https://newprairiepress.org/agstatconference

Part of the Agriculture Commons, and the Applied Statistics Commons (c) (1) (9)

This work is licensed under a Creative Commons Attribution-Noncommercial-No Derivative Works 4.0 License.

\section{Recommended Citation}

Anderson, D. M.; Murray, L. W.; Sun, P.; Fredrickson, E. L.; Estell, R. E.; and Nakamatsu, V. B. (2010). "CHARACTERIZING FORAGING PATTERNS AMONG CATTLE AND BONDED AND NON-BONDED SMALL RUMINANTS USING SPATIAL POINT PROCESS TECHNIQUES," Conference on Applied Statistics in Agriculture. https://doi.org/10.4148/2475-7772.1058

This is brought to you for free and open access by the Conferences at New Prairie Press. It has been accepted for inclusion in Conference on Applied Statistics in Agriculture by an authorized administrator of New Prairie Press. For more information, please contact cads@k-state.edu. 


\section{Author Information}

D. M. Anderson, L. W. Murray, P. Sun, E. L. Fredrickson, R. E. Estell, and V. B. Nakamatsu 


\title{
Characterizing Foraging Patterns among Cattle and Bonded and Non-bonded Small Ruminants using Spatial Point Process Techniques
}

\author{
D.M. Anderson ${ }^{1,5}$, L.W. Murray ${ }^{2}$, P. Sun ${ }^{3}$, E.L. Fredrickson ${ }^{1}$, R.E. Estell ${ }^{1}$, and V.B. Nakamatsu ${ }^{4}$ \\ ${ }^{1}$ U.S. Department of Agriculture, Agriculture Research Service, Jornada Experimental Range, \\ Box 30003, MSC 3JER NMSU, Las Cruces, NM 88003-8003, USA; ${ }^{2}$ Kansas State University, \\ Manhattan, KS 66605, USA; ${ }^{3}$ GlaxoSmithKline, Research Triangle Park, NC 27709-3398, USA; \\ ${ }^{4}$ INTA, Esquel Agroforestry Experimental Station, Chubut, Argentina; ${ }^{5}$ Corresponding author's \\ e-mail address: deanders@nmsu.edu
}

\begin{abstract}
This paper uses the technique of spatial point processes to describe the spatial patterns of freeranging cattle and small ruminants. Two mixed-species livestock groups were monitored while foraging on 410 ha of brush-infested Southern New Mexico rangeland during July and August 1988. The groups consisted of crossbred Bos taurus and Bos indicus beef cattle with white-faced sheep (Ovis aries) and mohair goats (Capra hircus). The bonded group consisted of small ruminants that had their behaviours modified through socialization with cattle to form a 'flerd' in which small ruminants consistently remained near cattle. Small ruminants in the non-bonded group had not been socialized with cattle. A subset of animal location data measured during the morning and afternoon over five days for both the bonded and non-bonded groups was analyzed for spatial patterns. Only data for five morning periods (7:00-8:00 a.m.) are reported because morning and afternoon spatial patterns were similar. Observed nearest neighbor distances, mean number of small ruminant near an arbitrary cow, and point-to-animal distances were compared to Monte Carlo simulations of independently and uniformly distributed animal locations. Bonded and non-bonded groups were also compared. Results suggested bonded and non-bonded groups were similar in spatial patterns of intra-specific distances for both cattle and small ruminants. However, bonding changed the repulsive relationship observed between cattle and non-bonded small ruminants stocked together to one of inter-specific attraction. Bonded small ruminants remained close to and formed inter-specific clusters with cattle. In addition, the mean number of bonded small ruminants near an arbitrary cow was consistently higher than for non-bonded small ruminants. Finally, the spatial pattern of cattle across the paddock did not differ between bonded and non-bonded groups, while bonded small ruminants tended to disperse slightly more uniformly across the paddock than did non-bonded small ruminants. These findings indicate the usefulness of spatial point processes techniques to analyze such animal location data, substantiate on a larger scale conclusions of previous, replicated studies about the effect of bonding small ruminants to cattle, and suggest utilization of paddock landscapes may be positively influenced using flerds compared to flocks and herds.
\end{abstract}

Keywords: mixed-species stocking, animal distribution, animal locations, cattle, sheep, goats, flerds. 


\section{INTRODUCTION}

Optimizing biological efficiency within plant-animal systems requires the correct combination of vegetation types, animal species and management (Cook, 1985; Soder et al., 2007). Among landscape stewardship issues, animal distribution remains the second most critical challenge for free-ranging animal managers once proper stocking rate has been established (Holechek et al., 1998). At least 68 different factors have been documented to affect animal distribution (Anderson, 2010) with age, breed, topography, vegetation distribution and water locations being particularly important in affecting sub-grouping among sheep (Dudzinski and Arnold, 1967).

Forage utilization results from the interaction among a number of dynamic plant, animal, weather and topographic factors that collectively affect animal distribution (Cook, 1966; Provenza and Launchbaugh, 1999). Distribution patterns result from preferences that arise at a variety of temporal and spatial scales (Bailey et al., 1996). The factors that control the use of space (animal distribution) by an animal or a species are still imperfectly understood, particularly in semi-arid and arid regions (Low, 1979). Many biotic and abiotic causes and consequences of spatial variation in livestock distribution have been reported (Hobbs, 1999; Kausrud et al., 2006).

Although mixed-species foraging may increase overall animal production (Nicol et al., 2005), mixed-species stocking of free-ranging large and small ruminants presents unique management challenges. It appears that sheep and goats do not necessarily spend the same amount of time engaging in the same activities under free-ranging conditions as do cattle (Squires, 1981; Kronberg and Malechek, 1997). Depending on the breed, sheep tend to form three general spatial patterns: tightly-knit flocks, widely-dispersed flocks, or flocks that disperse into many subgroups with nearest neighbor distances ranging from $1.7 \mathrm{~m}$ to $8.6 \mathrm{~m}$ (Arnold and Dudzinski, 1978). Furthermore, sheep prefer to associate with sheep of the same breed when given the choice (Arnold and Pahl, 1974) and have shorter grazing bouts than cattle (Rook et al., 1994). Thus domestic animal species differ in their behaviours. Even among physiologically similar dairy cattle, they demonstrated unique and discernable personality traits (Müller and Schrader, 2005) that impact their social structure (Slater, 1981). Therefore, it should be no surprise that mature cattle and sheep stocked simultaneously in the same paddock are seldom found foraging together (Squires, 1981).

Since at least 1962, it has been known that, under certain conditions, a social relationship could be formed between different species (Scott, 1962). Bond et al. (1967) reported that cohesiveness appeared to develop between sheep and cattle as a result of their being stocked together on small paddocks. An initial study by Anderson et al. (1987) established proof-of-concept that close confinement of sheep and cattle can create cohesiveness (termed a 'bond') between large and small ruminants, with the term 'flerd' (flock+herd) being used to denote the inter-specific association of small ruminant groups remaining with cattle under free-ranging conditions (Anderson et al., 1988). This initial work was followed by a series of replicated bonding studies which demonstrated readily-observed decreases in mean inter-specific separation between groups of cattle and bonded small ruminants foraging on arid rangeland and which investigated the effects of species (sheep and goats) and gender of small ruminants as well as the length of 
time small ruminants were in association with cattle to create a bond (Hulet et al., 1989; Hulet et al., 1991; Anderson et al., 1996; Fredrickson et al., 2001). In these studies, numbers of ovines per treatment group ranged between one and eight with or without three to seven caprines while bovine numbers in the treatment groups ranged between one and eight.

In July and August 1988, Nakamatsu (1989) conducted a study with two larger groups of animals (one bonded, one non-bonded) to collect data on sheep and cattle activity, weather, standing crop, livestock diets based on fecal composition and sheep liveweight change, as reported in Hulet et al. (1992). In addition, spatial data were collected to see whether previously observed patterns in the spatial distribution of small groups of bonded (flerd) and non-bonded (flock and herd) cattle and small ruminants were affected by increased animal group size and increased length of time over which data were collected. Analyses of animal location data both in Nakamatsu (1989) and in earlier bonding studies were extremely basic, focusing only on mean separation distances and hence did not look at general spatial patterns.

Therefore, the overall objective of this paper is to apply the statistical technique of spatial point processes to the animal spatial data collected by Nakamatsu (1989) to compare the spatial patterns of the two groups. Two specific objectives, related to the statistical analyses, are discussed in the following section.

\section{MATERIALS AND METHODS}

\subsection{Source of animal spatial data}

The experiment was conducted on the Jornada Experimental Range (JER; $32^{\circ} 30^{\prime}$ latitude; $106^{\circ}$ 45' longitude), located $37 \mathrm{~km}$ north of Las Cruces in southern New Mexico. The necessity to evaluate a large group with the resources available prevented the non-bonded and flerd livestock groups from being replicated. The issue of pseudo-replication as pertaining to this study is discussed below. The two groups were maintained separately and rotated between two paddocks (410 ha and 320 ha) that were similar in topography and vegetation.

Data presented here were collected for 14 days while each livestock group was in the larger 410 ha area, Paddock 10B: 13 July to 27 July 1988 for the non-bonded group and 27 July to 10 August 1988 for the bonded group (flerd). Rain received in Paddock 10B between July and September (the major period of growth) was $15 \mathrm{~mm}$ above the long term mean (1915-1988) of $129 \mathrm{~mm}$. Forage (10 grasses, 52 forbs and 5 shrub/cacti) in areas where intra- and inter-specific livestock groups foraged in Paddock 10B was similar $(\mathrm{P}>0.01)$ and abundant for both the nonbonded group and flerd field tests (Hulet et al., 1992).

Forty-two Hereford x Angus and Brangus heifers ranging in age between 18 and 40 mo were randomly allocated to the bonded and non-bonded animal groups. Cattle in the flerd consisted of 21 cows and one bull. Cattle in the non-bonded group consisted of 21 cows and two bulls. In the following, 'cow' will refer to both sexes. 
Thirty-one lambs and thirteen ewes $(n=44)$, previously bonded to cattle as described by Anderson et al. (1987), comprised the flerd. Thirty lambs and eighteen ewes $(n=48)$ not previously exposed to cattle were allocated to the non-bonded group. Most were of Rambouillet $\mathrm{x}$ Polypay breeding. Mean age of ewes and lambs was 14 and 6 mos, respectively. In addition, eleven Angora goats (6-8 mo old), previously bonded to sheep, were randomly allocated to each of the two groups ( $n=5$ to the flerd and $n=6$ to the non-bonded group). The goats behaved in a very similar manner to the sheep group to which they were assigned. Therefore, goats and sheep were considered as a single type of event, denoted 'small ruminants' (Nakamatsu, 1989).

To facilitate collection of animal-location data, a physical grid was set out in Paddock 10B, with $1.8 \mathrm{~m}$ steel T-posts set approximately every $400 \mathrm{~m}$. Attached to the T-posts were metal rectangles approximately $33 \mathrm{~cm}$ x $39 \mathrm{~cm}$ in size or metal disks approximately $90 \mathrm{~cm}$ in diameter on which were painted either letters or numbers, respectively. At hourly intervals, Nakamatsu (1989) determined each animal's location with respect to the T-grid using a range finder (Model 620 manufactured by Ranging, Inc., East Rochester, NY). These locations were then plotted on a scale map of Paddock 10B to obtain (x,y) coordinates for each animal in each time period.

Preliminary statistical analyses of Nakamatsu's animal location data were conducted separately for each livestock group by day and time, resulting in a total of 20 analyzed periods (Sun, 2001). The two selected times within a day (7:00-8:00 a.m. and 5:00-6:00 p.m.) represent periods when summer foraging typically occurs and differences in the spatial distribution of the flerd and the non-bonded groups, if any, should be most apparent. Sun's (2001) preliminary results indicated time of day did not result in substantive differences in animals' spatial patterns. Therefore, subsequent analyses reported in this paper use pooled data from the morning period only for the five observed days. Readers interested in afternoon results and specific days should consult Sun (2001).

\subsection{Statistical analysis using spatial point processes techniques}

Location data composed of (x, y) coordinates with an identifier (e.g., animal species, either cattle or small ruminants) constitutes a 'marked spatial point process'. Excellent, thorough references for spatial point processes (SPP) include Diggle (1983, 2003) and Upton and Fingleton (1985). As this technique has been used only rarely in animal behavior literature, we briefly discuss SPP concepts and techniques of analysis that relate specifically to the current research.

2.2.1 Null hypotheses of interest. For SPP, the null hypothesis of interest, also called a 'dividing hypothesis' by Diggle (1983, 2003), is whether animal locations are independently and uniformly distributed over the area of interest (Paddock 10B in this study), that is, whether they constitute a Poisson process. When the spatial distribution of animals of only one species is being considered (a 'univariate' SPP), the spatial pattern observed under the null hypothesis is termed 'complete spatial randomness' or CSR. In this application, CSR would also be termed 'intra-specific independence', i.e., the individual animals of a species are distributed uniformly and independently over the paddock. Under the alternative hypothesis, animals are aggregated (clustered) on one extreme, or regularly spaced on the other extreme (Diggle, 2003). When the 
relationship between cattle and small ruminants is being considered (a 'bivariate' SPP); the null hypothesis is one of between-species independence (BSI), or inter-specific independence, i.e., cattle and small ruminants distribute themselves independently and uniformly over the landscape. Under the alternative hypothesis, the relationship between cattle and small ruminants may be one of attraction (a positive spatial correlation) or repulsion (a negative spatial correlation).

Therefore, the first objective of this paper is to evaluate flerd and non-bonded groups separately for CSR and BSI. In addition, this research also focuses on whether spatial patterns seen in previous research between inter-specific livestock groups extend to a larger scale, that is, with a larger number of animals and over a longer time span. Therefore, the second objective of this work is to compare spatial patterns of the flerd and non-bonded groups.

2.2.2 Distance measures used to evaluate CSR and BSI. Three distance measures, based on Euclidean distances, were calculated for all animals in each group to examine CSR and BSI and to compare groups (Diggle, 1983, 2003; Upton and Fingleton, 1985):

1) nearest neighbor distances (NNDs; Clark and Evans, 1954) for cow-to-cow (C-C), small ruminant-to-small ruminant (SR-SR) and small ruminant-to-cow (SR-C), for all pairs of animals.

2) the mean number of small ruminants within a specified distance from an arbitrary cow, for all cows.

3) point-to-cow (P-C) and point-to-small ruminant (P-SR) distances, based on a 9 x 9 grid of 81 imaginary points evenly 'placed' across a map of Paddock 10B. Distance from each imaginary point to the nearest animal (cow or small ruminant) was calculated. The 9 x 9 grid was based on the recommendation of Diggle and Matern (1981) that the number on each axis of the grid $(\mathrm{k}=9)$ be approximately the square root of the number of animals (71 for flerd and 75 for the non-bonded group).

The first two measures are used to examine animal-to-animal spatial relationships which reflect social cohesiveness. The third measure is used to indicate animal distribution across the paddock, without reference to other animals.

2.2.3 Summarizing distance measures. Each of the three observed distance measures is summarized in an empirical distribution function (EDF) presented in a bivariate graph with distance in meters on the horizontal axis and cumulative percent or number of animals on the vertical axis (Diggle, 1983, 2003; Upton and Fingleton, 1985). Given the size of Paddock 10B, the maximum possible distance is approximately $3200 \mathrm{~m}$ but observed distances were rarely larger than $3000 \mathrm{~m}$; thus, the horizontal axis of all graphs is scaled from 0 to $3000 \mathrm{~m}$. The vertical axis for EDFs of nearest neighbor distances or point-to-animal distances is a cumulative percent, ranging from $0 \%$ (no animals within the specified distance) to $100 \%$ (all animals within the specified distance). The vertical axis for mean number of small ruminants within a specified distance of an arbitrary cow is the cumulative count of small ruminants within a specified distance of an arbitrary cow, which ranges from zero (no small ruminants, on average, within the specified distance of a cow) to the maximum number of small ruminants in the group (49 in the 
flerd and 54 in the non-bonded group). Note that each individual day has its own EDF (Sun, 2001), but that, in this paper, the individual daily EDFs have been pooled into one observed EDF (OEDF) graph that contains the lower, mean and upper cumulative percent (or count) calculated over the five days of observation (Diggle, 1983, 2003). This gives information on the stability of relative spatial patterns over time.

In addition, for each livestock group and each of the NND and point-to-animal distance measures, a mean distance was calculated for each of the five days. The five day-means were averaged to produce an overall mean distance and the standard deviation among daily means was also calculated.

2.2.4 Monte Carlo tests of CSR and BSI separately for each group. To see whether a livestock group exhibited CSR (for C-C and SR-SR NNDs and P-C and P-SR distances) or BSI (for SR-C NNDs and number of small ruminants near an arbitrary cow), two separate analyses were performed. First, for each livestock group, a Monte Carlo simulation (Metropolis and Ulam, 1949) was done to simulate 99 data sets (Diggle, 2003), each of which contained simulated locations for cattle (22 for the flerd and 23 for the non-bonded group) and small ruminants (49 for the flerd and 54 for the non-bonded group). Animal locations in each dataset were simulated assuming independence and uniform distribution of animals across the paddock (i.e., the null hypothesis of either CSR or BSI was true). The lower, mean and upper simulated EDFs (SEDFs) were calculated as for the OEDFs. In addition, the mean distance was calculated for each of the 99 simulated datasets for NNDs and point-to-animal distances. Observed and simulated EDFs were graphed together and visually compared over the range of possible distances $(0 \mathrm{~m}$ to $3000 \mathrm{~m})$ for each distance measure. Second, the 99 mean distances from the Monte Carlo simulations and the overall observed mean distance were ranked (Diggle, 2003) for each of the NNDs and point-to-animal distances. The test statistic was the rank of the observed mean out of 100. An 'extreme' rank, either 1 or 2 or 99 or 100 indicated that a livestock group was not CSR (or BSI), at an alpha level of $4 / 100=0.04$. We note that this is a standard test in SPP for which typically there will be only one OEDF (Diggle 1983, 2003) and hence pseudoreplication is not an issue for these CSR and BSI tests.

2.2.5 Testing differences between the two groups. To compare flerd versus non-bonded groups, two separate analyses were again performed. Observed EDFs were visually compared between the two groups over the range of possible distances. In addition, an approximate twoindependent sample t-test (with unequal variances) was performed using the overall distance mean and its standard deviation from each livestock group with conservative degrees of freedom equaling 4 (number of days minus 1). This provided a conservative test of mean differences. For this between-group test, unlike the within-group tests of CSR and BSI, pseudo-replication is an issue, especially when making inferences to a general population of such bonded and nonbonded groups and hence the results of these tests should be treated with caution. However, in this case, we are primarily interested in determining whether spatial patterns observed in this large-scale study are similar to those already documented in previous research with similar animals in a similar environment. Therefore, although these tests are based on replication over time, we believe these results deserve consideration. 
2.2.6 Statistical programs. Programs (Sun, 2001) to simulate locations under CSR or BSI and to calculate distance measures, mean, lower and upper distribution functions, and means from observed and simulated data were developed in SAS ${ }^{\circledR}$ using SAS ${ }^{\circledR}$ functions and the IML procedure (SAS ${ }^{\circ}$ Institute, 1989, 1990b). Empirical distribution functions were graphed using the SAS ${ }^{\circledR}$ GPLOT procedure (SAS ${ }^{\circledR}$ Institute, 1990a).

\subsection{Application of SPP to temporally-dynamic, spatially-dependent data}

There are three novel features of the SPP analyses of these animal location data, in comparison to classic examples of SPP (e.g., tree locations, archeological sites, and locations of galaxies; see Diggle, 1983, 2003, and Upton and Fingleton, 1985) and to previous research about animal spatial patterns. The first difference is that animal locations are dynamic on a brief temporal scale, in contrast to the stationary nature of most traditional SPP applications. Dudzinski et al. (1969, 1982) used nearest neighbor distances to characterize the spatial pattern of sheep and cattle, respectively, but did not use Monte Carlo techniques to actually test CSR. Dudzinski et al. (1969) used observed and simulated animal locations to obtain an empirical EDF and a simulated EDF, but only compared them descriptively. Dudzinski et al. (1982) used an approximate parametric test and an order-statistic-based test to determine departures from CSR. Our work uses standard Monte Carlo techniques for tests of CSR and BSI.

The second aspect involves replication. In typical research involving SPP for stationary objects, (e.g., tree locations), (x, y) coordinates are measured at one time across some defined sub-region, typical of the surrounding region, but distinct from that region, and separated only by arbitrary imaginary boundaries. In these cases, there is no true replication (Diggle, 1983, 2003) and it is therefore impossible to evaluate the consistency of the spatial pattern. Diggle (2003) notes that true replication has been rare in SPP applications, and that in traditional applications (like vegetation, archeological sites, and astronomy), pseudo-replication, obtained by partitioning a region into sub-regions, can be useful. Diggle (2003) also points out that analyses of traditional applications without replication are usually considered as 'model-based' (e.g., regression models), rather than 'design-based' (e.g., analysis of variance models).

In comparison with traditional applications of static events, this work has replication over time which allows evaluation of the variability of animal spatial patterns over time for these specific groups of animals. Replication over days allows the calculation of lower and upper OEDFs to examine the relative animal-to-animal (or point-to-animal) spatial pattern, which refers to animal locations relative to other animal locations (or points in the imaginary grid), not absolute locations in the paddock. Observed empirical distribution functions which display a 'narrow' upper-lower OEDF envelope indicate that the relative spatial pattern is very consistent over time, while the opposite is true if the upper-lower envelope is very wide. With respect to the absolute distribution of animals over Paddock 10B (i.e., the exact $(\mathrm{x}, \mathrm{y})$ coordinates of an animal at a specific time), the absolute location of individual animals or groups of animals continuously changed over days and times, as shown on animal-location maps (data not shown; see Sun, 2001). Therefore, we conclude that absolute animal locations are independent over time and 
hence days do not constitute pseudo-replication in the sense of correlated observations (Hurlburt, 1984). Dudzinski et al. (1969) used both true replication (aerial photographs of different paddocks) and pseudo-replication (multiple aerial photographs made at one time period in a single paddock of animal groups some distance apart). For the latter photographs, animal locations were considered as independent, given that photographs were taken at widely spaced intervals within large paddocks, and hence were treated as true replication.

Third, we note that 'edge effects' (Diggle, 1983, 2003) that have typically been a problem in traditional applications are not a concern in this research because animals were confined to Paddock 10B with no animals in adjacent paddocks. Previous research has demonstrated that for flerds to respond properly, it is necessary to keep adjoining paddocks free of animals, especially large ruminants, since the inter-specific bond arises predominantly from the behavior of small ruminants and appears to be species-specific, not individual-specific, meaning that a bonded small ruminant will follow any bovine that accepts its presence (Anderson, 1998). In other animal research involving nearest neighbor distances, Dudzinski et al. (1982) ignored 'edge effects' when reporting on the distribution of Shorthorn cattle on rangeland near Alice Springs, Australia.

\section{RESULTS}

Previous research by Anderson et al. (1987) defined bonding as having occurred if inter-specific distances were $\leq 322 \mathrm{~m}$, and the degree of bonding was considered strong if the distances were $\leq$ $161 \mathrm{~m}$. In this study, maps (data not shown) indicated that each subgroup of flerd cattle was usually accompanied by one or more small ruminants that were $\leq 322 \mathrm{~m}$ from the cattle In contrast, cattle and non-bonded small ruminants were usually separated $>322 \mathrm{~m}$ in space with small ruminants forming a single tight cluster, far from any cow subgroup. However, on at least one occasion (15 July 1988 between 5:00 and 6:00 p.m.), the cattle and small ruminants in the non-bonded group were relatively close together. This occurred in the very southeast corner of Paddock 10B and may have represented a time when livestock were entering or leaving the sole location for drinking water.

\subsection{Nearest neighbor distances (NNDs) to evaluate CSR (or BSI) and to compare flerd and non-bonded livestock groups}

\subsubsection{Intra-specific NNDs}

The graphs of OEDFs of intra-specific NNDs are visually similar for flerd C-C, non-bonded group C-C, flerd SR-SR, and non-bonded SR-SR (Figures 1 and 2). Two general conclusions can be drawn from Figures 1 and 2 with respect to CSR. First, the upper-lower OEDF envelope (which surrounds the mean OEDF) is consistently above the upper-lower SEDF envelope over the range of NNDs from $0 \mathrm{~m}$ to approximately $400 \mathrm{~m}$. This implies that these four sets of NNDs all display smaller NNDs than those predicted if animal locations were CSR. Therefore, cows were clustered (or aggregated) with other cows, and small ruminants were clustered with other small ruminants in both livestock groups. For the mean OEDF of both the flerd and non-bonded 
groups (Figure 1), 50\% of C-C NNDs were much smaller than $100 \mathrm{~m}$ and 100\% were $200 \mathrm{~m}$ or less. A similar pattern held true for small ruminants (Figure 2).

Second, because there is replication over days, we see that all four sets of OEDFs have very narrow upper-lower envelopes, indicating that the relative spatial pattern was very consistent across the five days. Absolute locations (i.e., (x, y) coordinates) changed both within and among days as indicated by maps (data not shown; see Sun 2001), but relative locations between animals did not. Interestingly, non-bonded small ruminants were slightly more clustered than those of the flerd, as indicated by the extremely narrow width of the upper-lower OEDF envelope over distances of $0 \mathrm{~m}$ to $100 \mathrm{~m}$ for non-bonded small ruminants (Figure 2).

The overall mean NND (averaged over the five days) ranged from $1.8 \pm 0.5 \mathrm{~m}$ for the nonbonded small ruminants to $24.0 \pm 14.6 \mathrm{~m}$ for flerd cattle (Table 1). For the Monte Carlo test of CSR using mean NND (Diggle, 2003), the overall mean NND for each of the four sets ranked $1^{\text {st }}$ in comparison to the 99 simulated NND means (Table 1). Thus we reject the null hypothesis that the mean NND of actual animal locations came from a SPP with CSR and conclude that mean NND was smaller than predicted under CSR, indicating there was a high degree of clustering among cows and among small ruminants in both livestock groups, on average.

The $t$-test of equality of mean flerd and non-bonded cow-to-cow NND is not significant $(t=1.49$, $p=0.2105$; Table 2), indicating that the two cattle groups had similar mean NNDs. In comparison, the $t$-test for small-ruminants is highly significant ( $t=5.54, p=0.0052$; Table 2$)$, with flerd small ruminants displaying a larger mean intra-specific NND (5.8 $\pm 1.5 \mathrm{~m})$ than nonbonded small ruminants (1.8 $\pm 0.5 \mathrm{~m}$; Table 1$)$. Thus, on average, small ruminants in the flerd were more dispersed, being about $4 \mathrm{~m}$ further apart from one another, than those of the nonbonded group. Thus for small ruminant-to-small ruminant NNDs, both the upper-lower OEDF envelope and the mean NND suggests that flerd small ruminants are statistically more dispersed, relative to one another, than non-bonded small ruminants.

\subsubsection{Inter-specific NNDs}

In marked contrast with intra-specific NNDs, flerd and non-bonded OEDFs show very different patterns for SR-C NNDs (Figure 3). For the flerd, the upper-lower OEDF envelope is consistently above the upper-lower SEDF envelope, indicating that the majority of small ruminant-to-cow NNDs was small. This pattern is similar to that of all four intra-specific NNDs and indicates a positive (i.e. attractive) spatial correlation between bonded small ruminants and cattle. For example, Figure 3 shows that $100 \%$ of the flerd SR-C NNDs were $200 \mathrm{~m}$ or less. These separation distances fall well within the $322 \mathrm{~m}$ criterion set by Anderson et al. (1987) for inter-specific cohesiveness or bonding. Furthermore, on three of the five days at 7:00-8:00 a.m., the mean SR-C NND was $<25 \mathrm{~m}$ and on all five days it was $<45 \mathrm{~m}$, slightly larger than the 14 m which was considered by Dudzinski et al. (1969) to be a reasonable estimate of the distance between nearest neighbors grazing in a cluster or group.

In comparison, the upper-lower OEDF envelope for the non-bonded group is mostly below the upper-lower SEDF envelope over the entire range of NNDs (0 m to $3000 \mathrm{~m}$ ), such that non- 
bonded SR-C NNDs were generally quite large. This observation indicates a negative (i.e., repulsive) spatial correlation between non-bonded small ruminants and cattle. For example, for the mean OEDF, none of the non-bonded small ruminants were within $200 \mathrm{~m}$ of the nearest cow (Figure 3) and the smallest inter-specific NND was at least $475 \mathrm{~m}$. In addition, Figure 3 shows that only $20 \%$ of the non-bonded SR-C NNDs were less than $600 \mathrm{~m}$.

With respect to consistency of the relative spatial pattern over the five days, the flerd OEDF exhibits a very narrow upper-lower envelope (Figure 3), similar to the intra-specific NND pattern. Thus the relative spatial pattern between small ruminants and cows was stable over time. In contrast, the non-bonded upper-lower OEDF envelope is extremely wide for NNDs (about 450 $\mathrm{m}$ to $2000 \mathrm{~m}$ ), indicating that the relative spatial pattern between non-bonded small ruminants and cows was very inconsistent over time. For example, on at least one day, no non-bonded small ruminants were within $450 \mathrm{~m}$ of a cow, while on another day, all non-bonded small ruminants were within $450 \mathrm{~m}$ of a cow.

The overall mean for flerd SR-C NNDs (averaged over the five days) was $31.3 \pm 14.8 \mathrm{~m}$, with a Monte Carlo rank of 1 (Table 1), the same rank as for all four intra-specific mean NNDs. Thus, we reject the null hypothesis of BSI and conclude that flerd small ruminants had a lower interspecific mean NND than expected if small ruminants behaved independently of cows, indicating an attractive relationship on average. In comparison, the overall mean for non-bonded SR-C NNDs was $1163.6 \pm 756.9$ m with a rank of 100 (Table 1). Thus, we again reject the null hypothesis of BSI but conclude that non-bonded small ruminants had a higher inter-specific mean NND than expected, indicating a repulsive relationship, on average.

The $t$-test of equality of mean flerd and non-bonded SR-C NNDs is significant $(t=-3.34, p=$ 0.0288; Table 2). On average, non-bonded small ruminants were over $1000 \mathrm{~m}$ farther from cows than flerd small ruminants.

Because EDFs have not been a commonly-used tool in animal behaviour studies, we note some further differences between flerd and non-bonded inter-specific OEDFs (Figure 3). First, in general, all OEDFs exhibit a pattern of steps or jumps across the scale of the horizontal axis (indeed, OEDFs are technically called 'step functions' in statistics). A small number of large steps occur in the OEDF graph for non-bonded SR-C NNDs (Figure 3). These large steps tend to occur because the single tight cluster of non-bonded small ruminants (seen in maps; see Sun, 2001) was of varying distances from the typical 1-4 subgroups of cows. In comparison, the OEDF for flerd SR-C NNDs appears smoother, i.e., displays more and smaller steps (Figure 3). This pattern occurs because cows in the bonded group also tended to break into several smaller subgroups (seen in maps; see Sun, 2001), but most subgroups were accompanied by one or more small ruminants. The smoother form of OEDF is also observed in the four intra-specific NNDs for similar reasons.

Sometimes the OEDF falls within the SEDF upper-lower envelope over some range of distance. For example, for the flerd group in Figure 3, over distances of $400 \mathrm{~m}$ and larger, the OEDF falls within the SEDF envelope. Over that scale of distance, the spatial pattern was not 
distinguishable from BSI and thus at distances of over $400 \mathrm{~m}$, flerd cattle and small ruminants were distributing themselves spatially independently.

\subsection{Mean number of small ruminants near an arbitrary cow to evaluate BSI and to compare flerd and non-bonded livestock groups}

Figure 4 shows the OEDFs of the mean number of small ruminants near an arbitrary cow for the flerd and non-bonded groups. As with SR-C NNDs, non-bonded and flerd groups exhibited very different spatial patterns. In the bonded group, the upper-lower OEDF envelope is consistently above the upper-lower SEDF envelope over a distance of $0 \mathrm{~m}$ to approximately $2700 \mathrm{~m}$, which is almost the maximum distance possible in Paddock 10B (Figure 4). This means there was almost always a higher number of small ruminants near an arbitrary cow in the flerd than expected under BSI. For example, within a distance of $200 \mathrm{~m}$ from a randomly selected cow, we would expect to see only 0 or 1 small ruminants according to the upper-lower SEDF envelope if cows and small ruminants behaved independently (Figure 4). However, based on the upper-lower OEDF envelope, a randomly-selected flerd cow had approximately 6 to 40 flerd small ruminants within $200 \mathrm{~m}$ (Figure 4). In addition, on average, the nearest flerd small ruminant was within less than $5 \mathrm{~m}$ of an arbitrary cow and all 49 flerd small ruminants were found within $1600 \mathrm{~m}$ of an arbitrary cow. The upper-lower OEDF envelope does not overlap the upper-lower SEDF envelope, as with the OEDFs for NNDs. This reinforces the conclusion drawn from flerd SR-C NNDs that flerd small ruminants had a consistent attractive spatial relationship with cattle.

In contrast, the upper-lower OEDF envelope for the mean number of non-bonded small ruminants within a specified distance of an arbitrary cow was extremely wide and surrounded the SEDF envelope, beginning at about $450 \mathrm{~m}$ (Figure 4). The OEDF envelope is so wide that it provides essentially no meaningful information about the number of small ruminants near an arbitrary cow. For example, the number of small ruminants within $500 \mathrm{~m}$ to $2000 \mathrm{~m}$ of an arbitrary cow was between 0 (none) and 54 (all) non-bonded small ruminants (Figure 4). From the mean OEDF (Figure 4), it is clear once the distance was reached where, on average, one small ruminant was 'near' a cow (i.e., at about $450 \mathrm{~m}$ ), the mean number of small ruminants near an arbitrary cow quickly increased to the total number of small ruminants (Figure 4). This pattern is very similar to that observed for non-bonded SR-C NNDs (Figure 3) and can be similarly explained by the fact that non-bonded small ruminants tended to associate in a single tight cluster (Figure 2) and had a repulsive spatial relationship with cattle (Figure 3).

\subsection{Point-to-animal distances to evaluate CSR and to compare flerd and non-bonded livestock groups}

Point-to-animal distances reflect animal distribution within Paddock 10B, ignoring other animals. In general, for P-C distances, the upper-lower OEDF envelope for both livestock groups is consistently below the upper-lower SEDF envelope (Figure 5), indicating that P-C distances were larger than expected under CSR for both livestock groups. Therefore, both flerd cows and cows with non-bonded sheep had clustered (not CSR or regular) spatial distributions across Paddock 10B and hence exhibited more spatial emptiness and lower paddock utilization at 
any one time than would be expected under CSR. Observed EDFs are similar between the two groups, both in terms of the mean OEDF and width of the OEDF envelope. For example, mean OEDFs for both groups show that approximately $8-10 \%$ and $60-65 \%$ of point-cow distances occurred at $200 \mathrm{~m}$ and $1000 \mathrm{~m}$, respectively, and the maximum point-to-cow distance was approximately $2100 \mathrm{~m}$ for both flerd and non-bonded groups.

The overall mean P-C distance (averaged over the five days) was $829.5 \pm 164.0 \mathrm{~m}$ and $896.4 \pm$ $159.6 \mathrm{~m}$ for flerd and non-bonded groups, respectively (Table 1). For the Monte Carlo test of mean P-C distance, both observed means have a rank of 100 out of 100 . Thus, for both flerd and non-bonded groups, we reject the null hypothesis of CSR and conclude that the mean P-C distance is larger than expected, indicating clustering in the paddock and hence non-uniform animal distribution within the paddock. The $t$-test of equality of mean flerd and non-bonded P-C distances is not significant ( $t=-.65, p=0.5514$; Table 2 ), indicating the two groups had similar mean point-to-cow distances and hence a similarly poor distribution of cows across the paddock, on average.

For P-SR distances, as with P-C distances, the upper-lower OEDF envelope is visually below the SEDF envelope for both flerd and non-bonded groups (Figure 6) but flerd and non-bonded groups exhibit somewhat different OEDFs and hence slightly different degrees of paddock emptiness. The mean OEDF of the flerd group is somewhat closer to the upper-lower SEDF than the non-bonded group mean OEDF, indicating a slightly lesser degree of emptiness, and hence a slightly more uniform distribution of flerd small ruminants than of non-bonded small ruminants (Figure 6). For example, the flerd OEDF shows that on average, about $8-10 \%$ of the P-SR distances were less than $200 \mathrm{~m}$ and $60-65 \%$ were less than $1000 \mathrm{~m}$, while $100 \%$ of the PSR distances were less than $2100 \mathrm{~m}$, which was very similar to flerd and non-bonded P-C distances (Figure 5). In addition, the width of the upper-lower OEDF envelope is similar to both flerd and non-bonded P-C OEDFs, indicating a similar degree of consistency of spatial pattern over days. This similarity implies the same degree and consistency of animal distribution within Paddock 10B of flerd small ruminants, flerd cattle, and cattle with non-bonded small ruminants.

In comparison, the non-bonded P-SR OEDF reveals that only about $2 \%$ of point-to-small ruminant distances were below $200 \mathrm{~m}$ and about 30\% were less than $1000 \mathrm{~m}$, while about 95\% were less than $3000 \mathrm{~m}$ (i.e., the maximum observed P-SR distance was over $3000 \mathrm{~m}$ ). Therefore, non-bonded small ruminants were generally very far from points in the imaginary grid (i.e., they were tightly localized in one part of the paddock at any one time). In general, this distribution pattern would translate into lower paddock utilization by non-bonded small ruminants compared to flerd small ruminants, flerd cattle, and cattle with non-bonded small ruminants. In addition, the non-bonded P-SR OEDF has a wider upper-lower envelope, indicating a less consistent relative spatial pattern over time than for flerd small ruminants.

The overall mean P-SR distance (averaged over five days) was $853.1 \pm 133.3 \mathrm{~m}$ and $894.4 \pm$ $119.9 \mathrm{~m}$ for flerd and non-bonded animals, respectively (Table 1). For the Monte Carlo test of mean P-SR distance, both means have a rank of 100 out of 100 . Thus for both flerd and nonbonded groups, we reject the null hypothesis of CSR and conclude that the mean P-SR distance 
was larger than expected, again indicating clustering and non-uniform distribution of small ruminants across Paddock 10B.

The $t$-test of equality of mean flerd and non-bonded P-SR distances is not significant $(t=-.52, p$ $=0.6305$; Table 2), indicating that flerd and non-bonded small ruminants exhibited a similar spatial distribution pattern within Paddock 10B based on the mean P-SR distance. This finding is somewhat contrary to the conclusion drawn from visual examination of the OEDFs, but the $t$ test focuses only on differences in the mean P-SR distances, whereas the OEDF examines information from all 81 individual imaginary points.

\section{CONCLUSIONS}

In this study, nearest neighbor distances and number of small ruminants near an arbitrary cow measure the social attraction or repulsion among animals while point-to-animal distances evaluate how animals distribute themselves over a landscape and hence reflect paddock utilization (or, equivalently, paddock non-use). In contrast to studies where environmental factors and standing crop distribution impacted the spatial relationship among animals (Dudzinski et al., 1969; Dudzinski and Schuh, 1978; Dudzinski et al., 1982), it is unlikely that the similarities and differences in animal spatial relationships reported here were impacted by differences in standing crop or weather but rather arose entirely from altered animal behaviour. Furthermore, since flock size and distribution over the landscape apparently do not appear related (Dudzinski and Arnold, 1967), our research suggests that the benefits of bonding may be extrapolated to even larger numbers of small ruminants than used in this study (see Podhordeski, 2010).

The statistical analyses applied to spatial point processes appear to provide a useful and quantitative tool to evaluate and predict animal locations within a landscape. This paper applies SPP techniques - previously primarily applied to objects for which positions relative to one another do not change over short time spans-to free-ranging animals exhibiting spatially and temporally dynamic behaviour. Although the Monte Carlo approach was used by Dudzinski et al. (1969) to describe intra-specific associations among sheep, this paper describes the first use of the Monte Carlo procedure to describe inter-specific as well as intra-specific animal associations within a landscape and to test spatial randomness and independence using formal Monte Carlo tests.

Although mapping animal locations on the landscape provides a visual and qualitative representation of where free-ranging animals occur on the landscape, in the past it has been labor- and time-intensive. However, with the advent of inexpensive, accurate and autonomous methods of gathering animal location data (e.g., Global Positioning System methods), we predict that in the future SPP techniques will be considered an important statistical tool when describing animal distribution patterns on landscapes. 


\section{DISCLAIMER}

Mention of a trade name, proprietary product or vendor does not constitute a warranty of the product by the USDA or New Mexico State University or imply its approval to the exclusion of other products or vendors that may also be suitable.

\section{ACKNOWLEDGEMENTS}

The field portion of this research was conducted in 1988 prior to the animal research program of the US Department of Agriculture - Agricultural Research Service, Jornada Experimental Range (USDA-ARS-JER) coming under the jurisdiction of New Mexico State Universities Institutional Animal Care and Use Committee (IACUC). Appreciation is expressed to colleagues and staff of the USDA-ARS-JER for helping to make this research possible especially for the animal husbandry and equipment maintenance required in order to obtain the field data. The authors further extend special thanks to the now-defunct New Mexico State University Statistics Center for providing the personnel and facilities to analyze these data as part of the masters degree requirements for Viviana Nakamatsu (July 1989) and Peixin Sun (November 2001).

\section{REFERENCES}

Anderson, D.M. 1998. Pro-active livestock management - capitalizing on animal behavior. J. Arid Land Studies. 7S:113-116.

Anderson, D.M. 2010. Geospatial methods and data analysis for assessing distribution of grazing livestock. Proceedings $4^{\text {th }}$ Grazing Livestock Nutrition Conference. (Hess, B.W., DelCurto, T., Bowman, J.G.P., Waterman, R.C. eds). West. Sect. Am. Soc. Anim. Sci., Champaign, IL, p. 57-90.

Anderson, D.M., Hulet, C.V., Shupe, W.L., Smith, J.N. and Murray, L.W. 1988. Response of bonded and non-bonded sheep to the approach of a trained border collie. Appl. Anim. Behav. Sci. 21:251-257.

Anderson, D.M., Hulet, C.V., Smith, J.N., Shupe, W. L. and Murray, L.W. 1987. Bonding of young sheep to heifers. Appl. Anim. Behav. Sci. 19:31-40.

Anderson, D.M., Estell, R.E., Havstad, K.M., Shupe, W.L., Libeau, R. and Murray, L.W. 1996. Differences in ewe and weather behavior when bonded to cattle. Appl. Anim. Behav. Sci. 47:201-209.

Arnold, G.W. and Dudzinski, M.L. 1978. Ethology of free-ranging domestic animals. Elsevier, New York.

Arnold, G.P. and Pahl, P.J. 1974. Some aspects of social behaviour in domestic sheep. Anim. Behav. 22:592-600.

Bailey, D.W., Gross, J.E., Laca, E.A., Rittenhouse, L.R., Coughenour, M.B., Swift D.M. and Sims, P.L. 1996. Mechanisms that result in large herbivore grazing distribution patterns. J. Range Manage. 49:386-400.

Bond. J., Carlson, G.E., Jackson, C., Jr. and Curry, W.A. 1967. Social cohesion of steers and sheep as a possible variable in grazing studies. Agron. J. 59:482-483. 
Clark, P.J. and Evans, F.C. 1954. Distance to nearest neighbor as a measure of spatial relationships in populations. Ecology. 35:445-453.

Cook, C.W. 1966. Factors affecting utilization of mountain slopes by cattle. J. Range Manage. 19:200-204.

Cook, C.W. 1985. Biological efficiency from rangelands through management strategies. In: Conference on Multispecies Grazing (Baker, F.H., Jones, R.K. eds). Winrock International, Morrilton, AR. p. 54-64.

Diggle, P.J. 1983. Statistical analysis of spatial point patterns. Academic Press, London, England.

Diggle, P.J. 2003. Statistical analysis of spatial point patterns, $2^{\text {nd }}$ edn. Arnold, London, England.

Diggle, P.J. and Matern, B. 1981. On sampling designs for the estimation of point-event nearest neighbor distributions. Scand. J. Statist. 7:80-84.

Dudzinski, M.L. and Arnold, G.W. 1967. Aerial photography and statistical analysis for studying behaviour patterns of grazing animals. J. Range Manage. 20:77-83.

Dudziński, M.L. and Schuh, H.J. 1978. Statistical and probabilistic estimators of forage conditions from grazing behaviour of merino sheep in a semi-arid environment. Appl. Anim. Ethol. 4:357-368.

Dudziński, M.L., Müller, W.J., Low, W.A. and Schuh, H.J. 1982. Relationship between dispersion behaviour of free-ranging cattle and forage conditions. Appl. Anim. Ethol. 8: 225-241.

Dudziński, M.L., Pahl, P.J. and Arnold, G.W. 1969. Quantitative assessment of grazing behaviour of sheep in arid areas. J. Range Manage. 22:230-235.

Fredrickson, E.L., Anderson, D.M., Estell, R.E., Havstad, K.M., Shupe, W.L. and Remmenga, M. 2001. Pen confinement of yearling ewes with cows or heifers for 14 days to produce bonded sheep. Small Rumin. Res. 2051:1-7.

Holechek, J.L., Pieper, R.D. and Herbel, C.H. 1998. Range management principles and practices. $3^{\text {rd }}$ edn. Prentice Hall Inc., Englewood Cliffs, N.J.

Hobbs, N.T. 1999. Responses of large herbivores to spatial heterogeneity in ecosystems. In: Nutritional ecology of herbivores: proceedings of the $5^{\text {th }}$ Int. Symp. On the nutrition of herbivores (Jung, H.J.G., Fahey, G.C. eds). Amer. Soc. Anim. Sci., Savory, IL, p. 97-129.

Hulet, C.V., Anderson, D.M., Smith, J.N., Shupe, W.L., Taylor, C.A., Jr. and Murray, L.W. 1989. Bonding of goats to sheep and cattle for protection from predators. Appl. Anim. Behav. Sci. 22:261-267.

Hulet, C.V., Anderson, D.M., Smith, J.N., Shupe, W. L. and Murray, L. W. 1991. Bonding of Spanish kid goats to cattle and sheep. Appl. Anim. Behav. Sci. 30:97-103.

Hulet, C.V., Anderson, D.M., Nakamatsu, V.B., Murray, L.W. and Pieper, R.D. 1992. Diet selection of cattle and bonded small ruminants grazing arid rangeland. Sheep Res. J. 8(1):1118.

Hurlburt, S.H. 1984. Pseudoreplication and the design of ecological field experiments. Ecol. Monographs. 64(2):187-211.

Kausrud, K., Mysterud, A., Rekdal, Y., Holand, Ø. and Austrheim, G. 2006. Densitydependent foraging behaviour of sheep on alpine pastures: effects of scale. J. Zool. 270:6371. 
Kronberg, S.L. and Malechek, J.C. 1997. Relationship between nutrition and foraging behavior of free-ranging sheep and goats. J. Anim. Sci. 75:1756-1763.

Low, W.A. 1979. Spatial and temporal distribution and behaviour. In: Aridland ecosystems: structure, functioning and management (Goodall, D.W., Perry, R.A., Howes, K.M.W. eds). Cambridge University Press, Melbourne, Australia, p. 779-795.

Metropolis, N. and Ulam, S. 1949. The Monte Carlo Method. J. Amer. Stat. Assn. 44:335-341.

Müller, R and Schrader, L. 2005. Behavioural consistency during social separation and personality in dairy cows. Behaviour 142:1289-1306.

Nakamatsu, V.B. 1989. Spatial behavior and diet selection of cattle and bonded and nonbonded small ruminants grazing arid rangeland. Unpublished Master's Thesis, New Mexico State University Statistics Center, 112 pp.

Nicol, A.M., Soper, M.B. and Stewart, A. 2005. Diversity of diet composition decreases with conjoint grazing of cattle with sheep and goats. In: Pastoral systems in marginal environments: Proceedings satellite workshop of the $20^{\text {th }}$ Int. Grassland Cong. Wageningen Academic Publ., Glasgow, Scotland, p. 126.

Podhordeski, J. 2010. Multi-species grazing: Profitable for your land; profitable for you. Saskatchewan, Canada. http//www.agriculture.gov.sk.ca/AGV_0909_11 Accessed Dec 20, 2010.

Provenza, F.D. and Launchbaugh, K.L. 1999. Foraging on the edge of chaos. In: Grazing behaviour of livestock and wildlife (Launchbaugh, K.L., Mosley, J.C., Sanders, K.D. eds). Pacific Northwest Range Short Course. Idaho For., Wildlife and Range Exp. Stn. Bull \#70, Moscow, ID, p. 1-12.

Rook, A.J., Huckle, C.A. and Penning, P.D. 1994. Effects of sward height and concentrate supplementation on the ingestive behavior of spring calving dairy cows grazing clover swards. Appl. Anim. Behav. Sci. 40:101-112.

SAS Institute Inc. 1989. SAS/IML Software: Usage and Reference, Version 6, First Edition. Cary, NC.

SAS Institute Inc. 1990a. SAS/GRAPH Software: Reference, Version 6, First Edition, Vol. 1. Cary, NC.

SAS Institute Inc. 1990b. SAS ${ }^{\circledR}$ Language: Reference, Version 6, First Edition. Cary, NC.

Scott, J.P. 1962. Introduction to animal behaviour. In: The behaviour of domestic animals (Hafez, E.S.E. ed). Williams and Wilkins Co., Baltimore, MD.

Slater, P.J.B. 1981. Individual differences in animal behavior. In: Perspectives in ethology: Advantages of diversity (Bateson, P.P.G. and Klopfer, P. eds). Plenum Press, New York.

Soder, K.J., Rook, A.J., Sanderson, M.A. and Goslee, S.C. 2007. Interaction of plant species diversity on grazing behavior and performance of livestock grazing temperate region pastures. Crop Sci. 47:416-425.

Squires, V.R. 1981. Livestock management in the arid zone. Inka Press, Melbourne, Australia.

Sun, P. 2001. Characterizing the spatial distribution of cows and small ruminants using animalto-animal distances and point-to-animal distances. Unpublished Masters Thesis, New Mexico State University Statistics Center, 201 pp.

Upton, G.H.G. and Fingleton, B. 1985. Spatial data analysis by example, Vol.1. John Wiley and Sons Ltd, Chichester, U. 
Table 1. Summary of observed empirical distribution functions (OEDFs) obtained in Jornada Experimental Range Paddock 10B and simulated empirical distribution functions (OEDFs and SEDFs, respectively) and tests of complete spatial randomness (CSR) or between species independence (BSI) with respect to nearest neighbor distances (NNDs), mean number of small ruminants near an arbitrary cow, and point-to-animal distances when evaluating a flerd and a non-bonded livestock group between 13 July and 10 August 1988.

\begin{tabular}{|c|c|c|c|c|}
\hline \multirow{2}{*}{$\begin{array}{c}\text { Measurements } \\
\text { (Associated Figure) }\end{array}$} & \multirow{2}{*}{ Visual comparison of OEDF \& SEDF } & \multicolumn{2}{|c|}{$\begin{array}{c}\text { Observed means } \pm \text { SD }(\mathrm{m}) \& \text { rank of observed } \\
\text { means }[]^{\mathrm{a}}\end{array}$} & \multirow[t]{2}{*}{ Spatial pattern interpretation } \\
\hline & & Flerd & Non-bonded group & \\
\hline \multicolumn{5}{|l|}{ Nearest neighbor distances } \\
\hline Cow to cow (Figure 1 ) & $\begin{array}{l}\text { Flerd and non-bonded: OEDF lies above } \\
\text { SEDF: there are more small NNDs than } \\
\text { expected with a tight OEDF envelope }\end{array}$ & $\begin{array}{c}24.0 \pm 14.6 \\
{[1 \text { out of } 100]}\end{array}$ & $\begin{array}{c}13.4 \pm 6.6 \\
{[1 \text { out of } 100]}\end{array}$ & Consistent clustering among cows \\
\hline $\begin{array}{l}\text { Small ruminant to small ruminant } \\
\text { (Figure 2) }\end{array}$ & Same as above for cattle & $\begin{array}{c}5.8 \pm 1.5 \\
{[1 \text { out of } 100]}\end{array}$ & $\begin{array}{c}1.8 \pm 0.5 \\
{[1 \text { out of } 100]}\end{array}$ & $\begin{array}{l}\text { Consistent clustering among small } \\
\text { ruminants }\end{array}$ \\
\hline Small-ruminant-to-cow (Figure 3) & $\begin{array}{l}\text { Flerd: OEDF lies above SEDF: there are } \\
\text { more than expected small NNDs } \\
\text { Non-bonded: OEDF lies below SEDF: } \\
\text { there are more than expected large NNDs }\end{array}$ & $\begin{array}{l}31.3 \pm 14.8 \\
{[1 \text { out of } 100]}\end{array}$ & $\begin{array}{c}1163.6 \pm 756.9 \\
{[100 \text { out of } 100]}\end{array}$ & $\begin{array}{l}\text { Consistent attraction or repulsion } \\
\text { between small ruminants and cattle } \\
\text { within flerd and non-bonded } \\
\text { groups, respectively }\end{array}$ \\
\hline $\begin{array}{l}\text { Mean number of small ruminants near an } \\
\text { arbitrary cow (Figure } 4 \text { ) }\end{array}$ & $\begin{array}{l}\text { Flerd: OEDF lies above SEDF: there are } \\
\text { more than expected small ruminants near } \\
\text { an arbitrary cow at any specific distance } \\
\text { Non-bonded: OEDF lies both above and } \\
\text { below SEDF: for small distances }<50 \mathrm{~m} \\
\text { there are few small ruminants, while for } \\
\text { larger distances, the OEDF envelope } \\
\text { contains SEDF envelope }\end{array}$ & $\begin{array}{l}\text { Example: Distance of } \\
100 \text { m: between } \sim 0.25 \\
\text { and } 49 \text { (all) small } \\
\text { ruminants expected } \\
\text { near an arbitrary cow }\end{array}$ & $\begin{array}{l}\text { Example: Distance of } \\
100 \text { m: between } 0 \text { and } 54 \\
\text { (all) small ruminants } \\
\text { expected near an } \\
\text { arbitrary cow }\end{array}$ & $\begin{array}{l}\text { Flerd: Consistent attraction } \\
\text { between small ruminants and cattle } \\
\text { Non-bonded: Small ruminants and } \\
\text { cattle show repulsion over small } \\
\text { distances, with independence of } \\
\text { movement over larger distances }\end{array}$ \\
\hline$\frac{\text { Point to animal distances }}{\text { Cow (Figure 5) }}$ & $\begin{array}{l}\text { Flerd and nonbonded: OEDF lies below } \\
\text { SEDF so there are more than expected } \\
\text { large point-to cow distances }\end{array}$ & $\begin{array}{l}829.5 \pm 164.0 \\
{[100 \text { out of } 100]}\end{array}$ & $\begin{array}{c}896.4 \pm 159.6 \\
{[100 \text { out of } 100]}\end{array}$ & $\begin{array}{l}\text { High aggregation within Paddock } \\
\text { 10B, implying low paddock } \\
\text { utilization at any one time }\end{array}$ \\
\hline Small ruminant (Figure 6) & Same as above for cattle & $\begin{array}{c}853.1 \pm 133.3 \\
{[100 \text { out of } 100]}\end{array}$ & $\begin{array}{c}894.4 \pm 119.9 \\
{[100 \text { out of } 100]}\end{array}$ & Same as above \\
\hline
\end{tabular}

${ }^{\mathrm{a}}$ Monte Carlo Test of CSR (or BSI) using the rank of the observed mean based on n = 100 total samples (One Observed, 99 Simulated). 
Table 2. Summary of observed empirical distribution functions (OEDFs) obtained in Jornada Experimental Range Paddock 10B with approximate t-tests of equality of treatment means for two independent samples where Ho: Flerd - Non-bonded $=0$ for nearest neighbor distances (NNDs) and point-to-animal distances when evaluating a flerd and a non-bonded livestock group between 13 July and 10 August 1988.

\begin{tabular}{|c|c|c|c|c|}
\hline \multirow{2}{*}{ Measurements } & \multirow{2}{*}{ Visual comparison of OEDFs } & \multicolumn{2}{|c|}{ Approximate $t$ test } & \multirow{2}{*}{ Spatial pattern interpretation } \\
\hline & & d.f. $^{\mathrm{a}}=4$ & o.s.l. ${ }^{\mathrm{b}}$ of $|t|$ & \\
\hline \multicolumn{5}{|l|}{ Nearest neighbor distances } \\
\hline Cow to cow & $\begin{array}{l}\text { The non-bonded OEDF envelope fits inside the flerd } \\
\text { OEDF envelope indicating a strong overlap }\end{array}$ & 1.49 & 0.2105 & $\begin{array}{l}\text { No difference in NND distribution } \\
\text { between flerd and non-bonded cattle }\end{array}$ \\
\hline Small ruminant to small ruminant & $\begin{array}{l}\text { OEDFs for flerd and non-bonded are mostly overlapping } \\
\text { but with non-bonded group exhibiting tighter clustering } \\
\text { than the flerd }\end{array}$ & 5.54 & 0.0052 & $\begin{array}{l}\text { A difference in NND distribution } \\
\text { with flerd small ruminants less } \\
\text { tightly clustered than non-bonded } \\
\text { small ruminants }\end{array}$ \\
\hline Small-ruminant-to-cow & $\begin{array}{l}\text { OEDFs for flerd and non-bonded group are on opposite } \\
\text { sides of the SEDFs }\end{array}$ & -3.34 & 0.0288 & $\begin{array}{l}\text { A difference in NND distribution } \\
\text { with flerd small ruminants remaining } \\
\text { much closer to cattle than non- } \\
\text { bonded small ruminants }\end{array}$ \\
\hline $\begin{array}{l}\text { Mean number of small ruminants near } \\
\text { an arbitrary cow }\end{array}$ & $\begin{array}{l}\text { OEDF for flerd is above the SEDF indicating a somewhat } \\
\text { consistent, large number of small ruminants near an } \\
\text { arbitrary cow, while OEDF for the non-bonded group } \\
\text { show a very erratic pattern, which included independence }\end{array}$ & $\mathrm{n} / \mathrm{a}$ & $\mathrm{n} / \mathrm{a}$ & $\mathrm{n} / \mathrm{a}$ \\
\hline \multicolumn{5}{|l|}{ Point to animal distances } \\
\hline Cow & $\begin{array}{l}\text { OEDF for the flerd and non-bonded group are mostly } \\
\text { overlapping, indicating similar low paddock utilization } \\
\text { (i.e., high emptiness) }\end{array}$ & -0.65 & 0.5514 & $\begin{array}{l}\text { No difference in point-to-animal } \\
\text { distances distribution of flerd and } \\
\text { non-bonded group }\end{array}$ \\
\hline Small ruminant & $\begin{array}{l}\text { OEDFs for flerd and non-bonded group are mostly } \\
\text { overlapping, indicating similar low paddock utilization, } \\
\text { although flerd small ruminant exhibit slightly more } \\
\text { consistency of pattern (narrower OEDF envelope) and } \\
\text { slightly more spread }\end{array}$ & -0.52 & 0.6305 & Same as above \\
\hline
\end{tabular}

d.f. = degrees of freedom

b.s.l. = observed significance level 

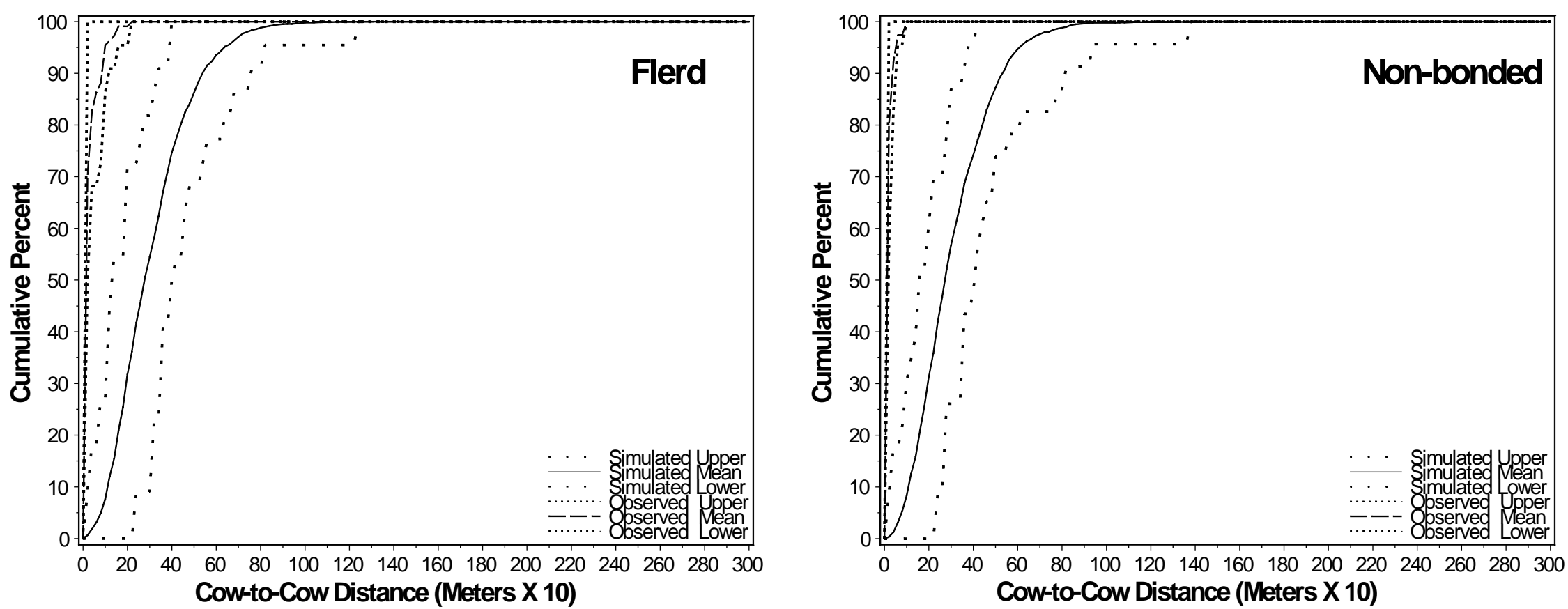

Figure 1. Mean empirical distribution functions (EDFs) for cow-to-cow nearest neighbor distances (NNDs) in Jornada Experimental Range Paddock 10B between 7:00 and 8:00 a.m. over five days graphed as cumulative percent versus distance for a flerd composed of 22 cattle and 49 small ruminants (sheep and goats) beginning 30 July 1988 and a non-bonded group composed of 23 cattle and 54 small ruminants beginning 14 July 1988. The mean, lower and upper observed and simulated EDFs are summarized from NNDs calculated from actual and simulated cow locations. For the 99 simulated datasets cow locations were simulated by the Monte Carlo method to be independently and uniformly distributed. 


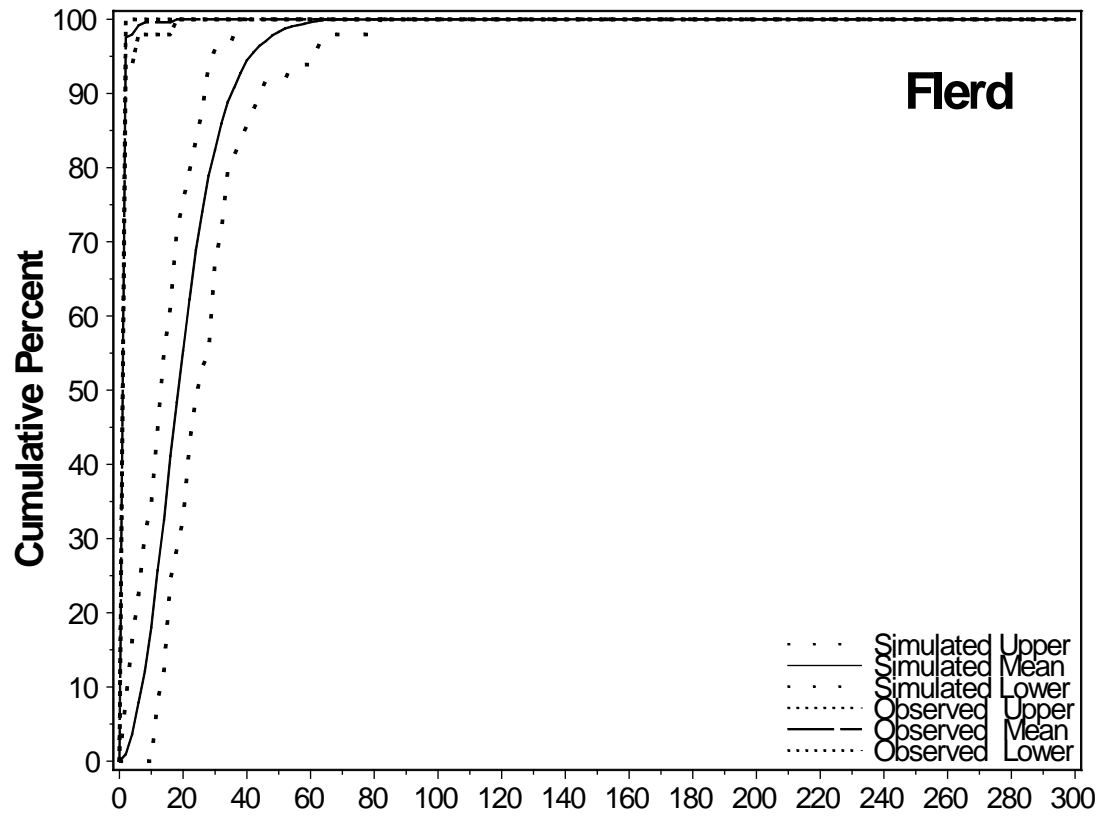

Small Ruminant-to-Small Ruminant Distance (Meters X 10)

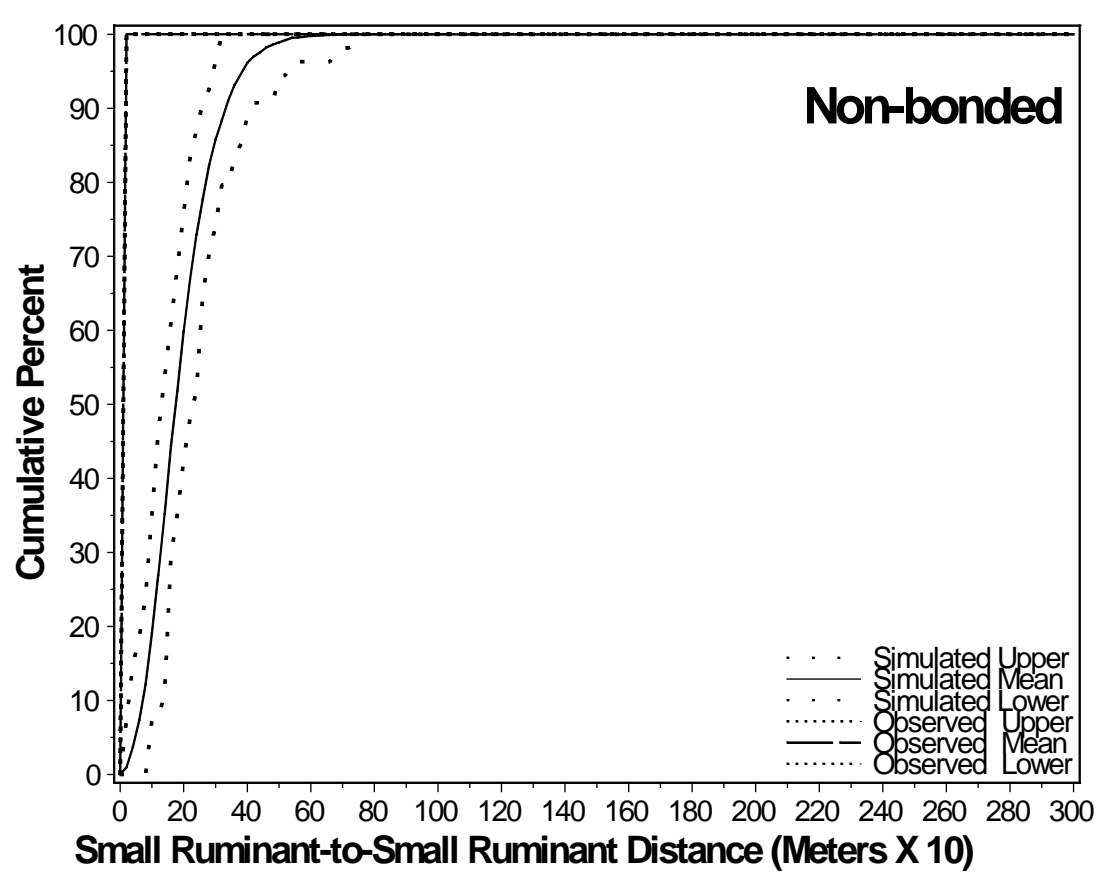

Figure 2. Mean empirical distribution functions (EDFs) for small ruminant-to-small ruminant nearest neighbor distances (NNDs) in Jornada Experimental Range Paddock 10B between 7:00 and 8:00 a.m. over five days graphed as cumulative percent versus distance for a flerd composed of 22 cattle and 49 small ruminants (sheep and goats) beginning 30 July 1988 and a non-bonded group composed of 23 cattle and 54 small ruminants beginning 14 July 1988. The mean, lower and upper observed and simulated EDFs are summarized from NNDs calculated from actual and simulated small ruminant locations. For the 99 simulated datasets small ruminant locations were simulated by the Monte Carlo method to be independently and uniformly distributed. 

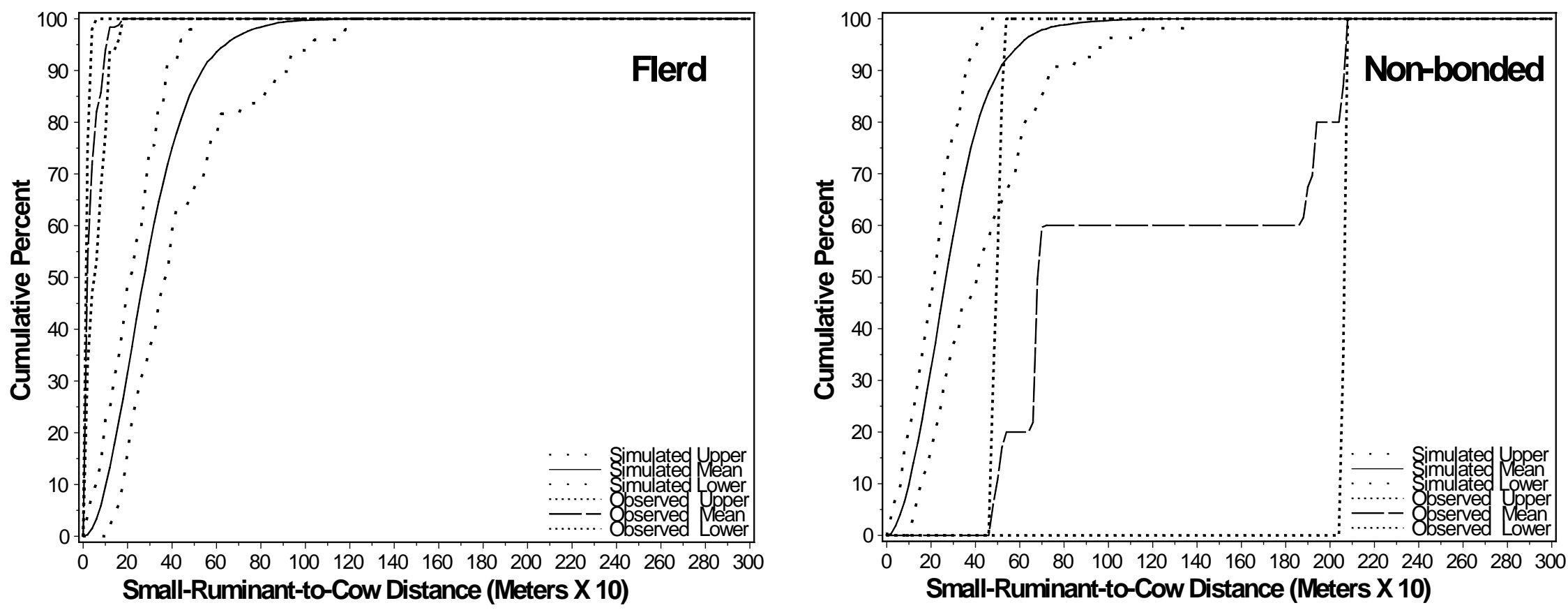

Figure 3. Mean empirical distribution functions (EDFs) for small ruminant-to-cow nearest neighbor distances (NNDs) in Jornada Experimental Range Paddock 10B between 7:00 and 8:00 a.m. over five days graphed as cumulative percent versus distance for a flerd composed of 22 cattle and 49 small ruminants (sheep and goats) beginning 30 July 1988 and a non-bonded group composed of 23 cattle and 54 small ruminants beginning 14 July 1988. The mean, lower and upper observed and simulated EDFs are summarized from NNDs calculated from actual and simulated animal locations. For the 99 simulated datasets animal locations were simulated by the Monte Carlo method to be independently and uniformly distributed. 

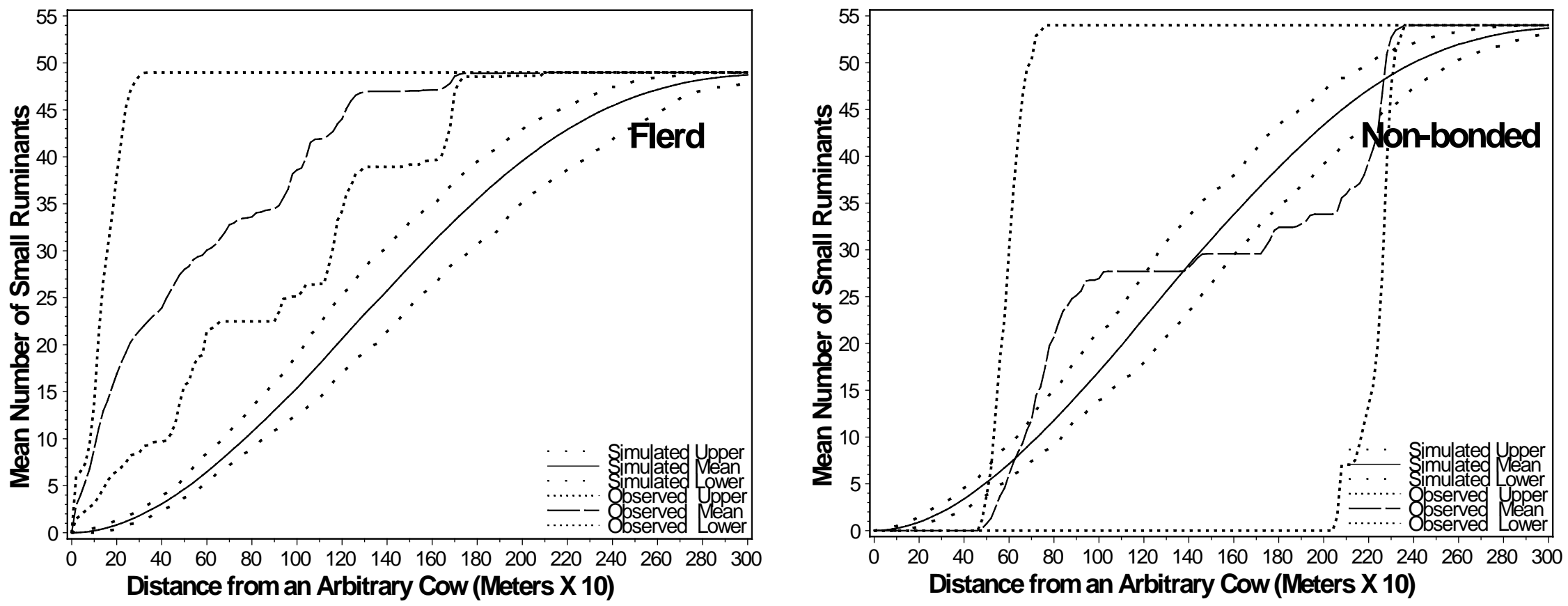

Figure 4. Mean empirical distribution functions (EDFs) for mean number of small-ruminants near an arbitrary cow in Jornada Experimental Range Paddock 10B between 7:00 and 8:00 a.m. over five days graphed as cumulative count versus distance for a flerd composed of 22 cattle and 49 small ruminants (sheep and goats) beginning 30 July 1988 and a non-bonded group composed of 23 cattle and 54 small ruminants beginning 14 July 1988. Cumulative counts are zero to 49 for the flerd and zero to 54 for the non-bonded group. The mean, lower and upper observed and simulated EDFs are summarized from small ruminant counts calculated from actual and simulated animal locations. For the 99 simulated datasets animal locations were simulated by the Monte Carlo method to be independently and uniformly distributed. 

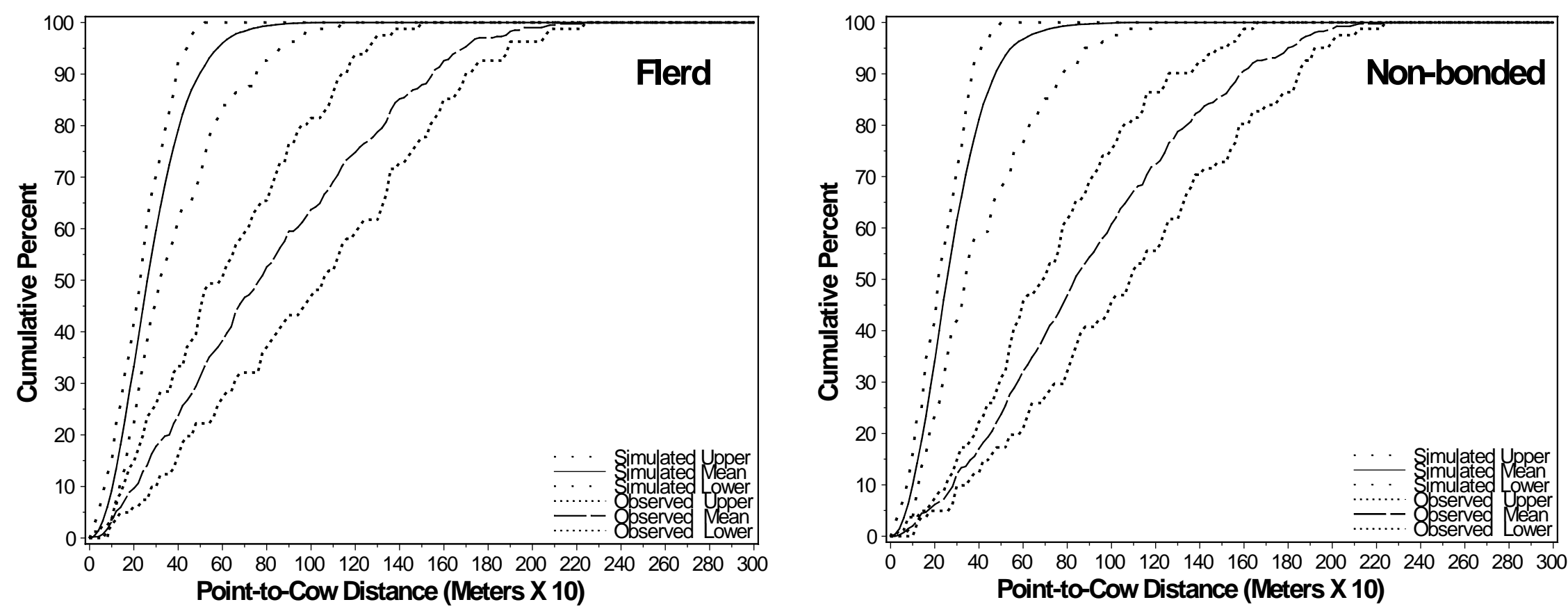

Figure 5. Mean empirical distribution functions (EDFs) for point-to-cow distances (PCDs) in Jornada Experimental Range Paddock 10B between 7:00 and 8:00 a.m. over five days graphed as cumulative percent versus distance for a flerd composed of 22 cattle and 49 small ruminants (sheep and goats) beginning 30 July 1988 and a non-bonded group composed of 23 cattle and 54 small ruminants beginning 14 July 1988. 'Points' are 81 imaginary locations spread in an evenly-spaced systematic grid within the paddock. The mean, lower and upper observed and simulated EDFs are summarized from PCDs calculated from actual and simulated cow locations. For the 99 simulated datasets cow locations were simulated by the Monte Carlo method to be independently and uniformly distributed. 

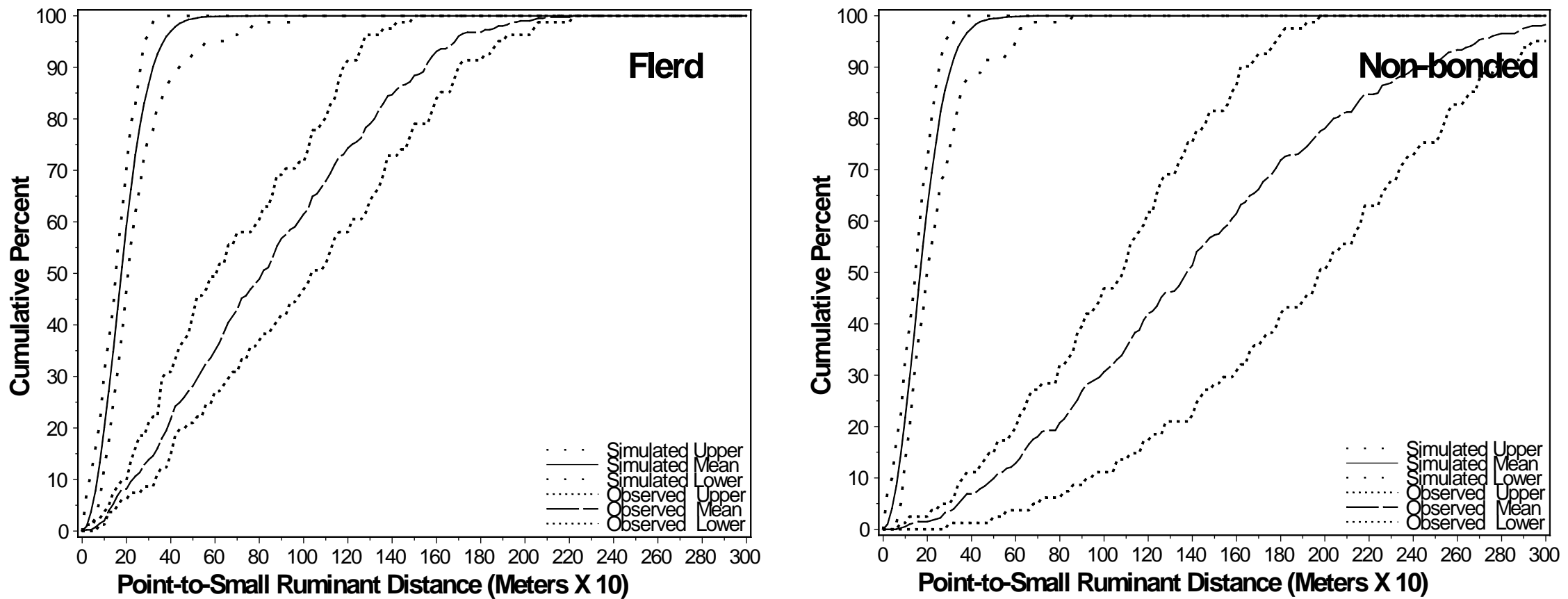

Figure 6. Mean empirical distribution functions (EDFs) for point-to-small ruminant distances (PSDs) in Jornada Experimental Range Paddock 10B between 7:00 and 8:00 a.m. over five days graphed as cumulative percent versus distance for a flerd composed of 22 cattle and 49 small ruminants (sheep and goats) beginning 30 July 1988 and a non-bonded group composed of 23 cattle and 54 small ruminants beginning 14 July 1988. 'Points' are 81 imaginary locations spread in an evenly-spaced systematic grid. The mean, lower and upper observed and simulated EDFs are summarized from PSDs calculated from observed and simulated small-ruminant locations. For the 99 simulated datasets small-ruminant locations were simulated by the Monte Carlo method to be independently and uniformly distributed. 